\title{
Medication Adherence and Coping with Disease in Patients from a Neurological Clinic: An Observational Study
}

\author{
Gabriele Helga Franke (iD) \\ Julia Nentzl' \\ Melanie Jagla-Franke \\ Tino Prell (iD) 2,3 \\ 'Department of Applied Human Sciences, \\ Magdeburg-Stendal University of Applied \\ Sciences, Stendal, Germany; \\ ${ }^{2}$ Department of Neurology, Jena \\ University Hospital, Jena, Germany; \\ ${ }^{3}$ Center for Healthy Ageing, Jena \\ University Hospital, Jena, Germany
}

\begin{abstract}
Purpose: Medication non-adherence is a huge concern for the medical community. For chronic, especially neurological diseases, taking medication is a central pillar of treatment. To improve adherence to these oftentimes complex medication regimens, the construct needs to be understood in more depth. The aim of this study was to investigate associations between adherence with sociodemographics, clinical variables, and coping in neurological patients.
\end{abstract}

Patients and Methods: The sample consisted of 545 patients from a German neurological clinic. Adherence was assessed with the Stendal Adherence to Medication Score (SAMS). Patients were grouped as completely adherent (SAMS $=0$ ), non-adherent (upper $25 \%$ of the sample), and moderately adherent. Associations with coping were assessed using the Essen Coping Questionnaire.

Results: Medication adherence was low compared to other non-neurological patient samples. Differences between adherence groups were found regarding gender and facets of coping, namely "trivialisation, wishful thinking and defence" and "finding of inner stability". Conclusion: Interventions to improve medication adherence should focus on facets of coping with disease, increasing acceptance of disease, willpower, and confidence in treatment.

Keywords: nervous system, compliance, self-report, coping with disease

\section{Introduction}

Low adherence to prescribed medication - meaning the extent to which the behavior of patients is consistent with the medical recommendations with which they have agreed ${ }^{1}$ - is an ever-present and complex problem, especially for patients with a chronic illness: about $25 \%$ of patients do not take their drugs as prescribed. $^{2,3}$ Overall, almost 200 different variables have been studied in their ability to predict adherence, but none of them is consistently associated. ${ }^{4}$

Up to now, most investigations of non-adherence in patients with chronic diseases focused on arterial hypertension, diabetes mellitus, and asthma. ${ }^{1,5}$ Regarding neurological diseases, medication adherence is often investigated in patients with epilepsy . Pharmacotherapy is substantial to the treatment of epilepsy, but insufficient adherence varies in patients with epilepsy from $26 \%$ to $79 \%$ between studies and is associated with a higher risk for seizures and mortality. ${ }^{6,7}$ Predictors of inadequate adherence include adolescence or young adulthood, the number of drugs and doses to be taken, lack of social support, a poor physician-patient relationship, and disease-related anxieties and
Correspondence: Tino Prell Department of Neurology, Jena University Hospital, Jena, Germany Email Tino.prell@med.uni-jena.de 
stigmatization experiences. In addition, adequate knowledge of the disease and therapy is a premise for adherence, ${ }^{8}$ although this often is insufficient in epilepsy patients. ${ }^{9,10}$

Medication non-adherence is also of special importance in patients with Parkinson's disease - a disease that affects $2 \%$ of those over the age of $65 .{ }^{11} \mathrm{~A}$ study revealed that $61 \%$ of patients with Parkinson's disease were non-adherent and that the average medical cost per non-adherent patient was $\$ 15,826$, compared to $\$ 9,228$ for adherent patients. ${ }^{12}$ People with Parkinson's disease often have complex drug regimens, which in progressed disease stages often involve taking different drugs at different times of the day, ${ }^{13}$ all of which have a negative impact on adherence. ${ }^{14,15}$ Studies associated nonadherence to young age, ${ }^{14}$ as well as old age. ${ }^{16}$ Similar to other chronic diseases, factors such as solitary living, low income, poor knowledge of the disease, cognitive impairment, and depression have a negative impact on adherence. ${ }^{17,18}$

Since measuring the medication blood level - as the most reliable method - is also the most expensive, self-report instruments for assessing medication adherence are often the only economic way to determine the construct. A systematic review identified 43 self-report scales to assess medication adherence. ${ }^{19}$ To date, meta-analyses and reviews on the question of medication adherence have concluded that the Morisky score $^{20,21}$ for blood-pressure therapies is the most frequently used self-report, but certainly not the gold standard. ${ }^{22}$ Since this score only has a "yes-no" answer format and only captures the forgetting of the intake, the carelessness in handling as well as the self-determined discontinuation of the drugs, a new instrument with more items and an expanded answer format was developed. This instrument is called "Stendal Adherence to Medication Score" (SAMS). Applying the ABC Taxonomy from the European Ascertaining Barriers to Compliance Consortium $^{23}$ and World Health Organization recommendations, ${ }^{24}$ a recent review on rating scales assessing adherence in Parkinson's disease concluded that the SAMS like the Morisky score - assesses both factors of adherence (intentional and non-intentional), and two out of five dimensions of adherence (namely patient and therapy). ${ }^{25}$ Regarding the phases of adherence, the Morisky score and the SAMS assesses the implementation and discontinuation of medication, but the SAMS additionally assesses the initiation of medication.

Neurological diseases in particular can have extensive consequences on the physical, emotional and cognitive level. Patients have to cope with symptoms, treatments, functional impairment, comorbidity and uncertainty about the course of the disease. ${ }^{26}$ How people with chronic diseases cope with disabilities and the impact of the disease on daily life, as well as the coping resources they use, can have an enormous impact on their quality of life. ${ }^{27,28}$ In the existing literature, the categorization into active and passive coping has become established to describe disease processing in several neurological disorders. For example, numerous studies showed that passive coping strategies are associated with a poorer health-related quality of life and poorer physical health in Parkinson's disease. ${ }^{29-33}$ In this exploratory study, the use of the SAMS was tested in a sample of patients from a neurological clinic. Different levels of adherence were investigated regarding associations with sociodemographic factors, treatment specifics, as well as coping strategies. This is intended to deepen the understanding of medication adherence of neurological patients to develop specific interventions to improve problematic behavior.

\section{Method}

\section{Sample}

This observational study was approved by the local ethics committee of the Jena University Hospital (4572-10/15). All subjects gave written informed consent in accordance with the Declaration of Helsinki. From January to May 2018, 779 patients who were treated in the Department of Neurology at the Jena University Hospital (inpatient and outpatient) completed a questionnaire assessment. An accruing random sample was investigated in a particular time slot. After this time slot, this study was finished. Therefore, the gathered sample made it possible to draw an image of neurological patients in a single centre. Of this initial sample, which is further described in the SAMS manual, ${ }^{34}$ we investigated a subsample of $N=545$ who provided full questionnaire data. The patients who were excluded due to missing data did not differ in terms of level of adherence $(p=0.798)$ or gender $(p=0.299)$, but were on average 6.5 years older $(p<$ 0.001) than the 545 subjects included in this study. Sociodemographic data of this sample are presented in Table 1. The mean age of the sample was 62.6 years $( \pm 15.94,18-94)$, with the majority being male $(58.7 \%)$, married (63.8\%), and living with others (79.5\%). Most of the participants had a middle school $(37.3 \%)$ or high school degree (35.0\%) and did not work (76.7\%). Two-thirds of those who had a provided diagnosis reported to have a neurological disorder $(68.0 \%)$. Less than $0.6 \%$ reported to have dementia. For more detailed information on the diagnoses, see Figure 2. 
Table I Sociodemopgraphic Data for Adherence Groups

\begin{tabular}{|c|c|c|c|c|c|}
\hline Variable & $\begin{array}{l}\text { Completely } \\
\text { Adherent }\end{array}$ & $\begin{array}{l}\text { Moderately } \\
\text { Adherent }\end{array}$ & $\begin{array}{l}\text { Non- } \\
\text { Adherent }\end{array}$ & Total Sample & $\begin{array}{l}\text { Group } \\
\text { Comparison }\end{array}$ \\
\hline$N$ & 85 & 326 & 134 & 545 & \\
\hline $\begin{array}{l}\text { Sex: Male } \\
\text { Female }\end{array}$ & $\begin{array}{l}4 I(48.2 \%) \text { । } \\
44(51.8 \%)_{1}\end{array}$ & $\begin{array}{l}204(62.6 \%)_{2} \\
122(37.4 \%)_{2}\end{array}$ & $\begin{array}{l}75(56.0 \%)_{I, 2} \\
59(44.0 \%)_{I, 2}\end{array}$ & $\begin{array}{l}320(58.7 \%) \\
225(41.3 \%)\end{array}$ & $\begin{array}{l}\chi^{2}=6.27 \\
p<0.043\end{array}$ \\
\hline $\begin{array}{l}\text { Age: } M(S D) \\
\text { Age 18-64 } \\
\text { Age 65+ } \\
\text { Missing }\end{array}$ & $\begin{array}{l}65.25 \pm 15.57 \\
28(37.3 \%) \\
47(62.7 \%) \\
10\end{array}$ & $\begin{array}{l}63.12 \pm 15.80 \\
137(45.1 \%) \\
167(54.9 \%) \\
22\end{array}$ & $\begin{array}{l}62.34 \pm 16.43 \\
60(46.9 \%) \\
68(53.1 \%) \\
6\end{array}$ & $\begin{array}{l}62.64 \pm 15.94(18- \\
90) \\
225(44.4 \%) \\
282(55.6 \%) \\
38\end{array}$ & $\begin{array}{l}F=1.20 \\
p<0.303 \\
\chi^{2}=1.89 \\
p<0.389\end{array}$ \\
\hline $\begin{array}{l}\text { Marital status } \\
\text { Single } \\
\text { Married } \\
\text { Widow/Divorced } \\
\text { Missing }\end{array}$ & $\begin{array}{l}8(9.9 \%) \\
51(63.0 \%) \\
22(27.2 \%) \\
4\end{array}$ & $\begin{array}{l}57(17.6 \%) \\
209(64.5 \%) \\
58(17.9 \%) \\
2\end{array}$ & $\begin{array}{l}25(19.1 \%) \\
82(62.6 \%) \\
24(18.3 \%) \\
3\end{array}$ & $\begin{array}{l}90(16.8 \%) \\
342(63.8 \%) \\
104(19.4 \%) \\
9\end{array}$ & $\begin{array}{l}\chi^{2}=5.87 \\
p<0.209\end{array}$ \\
\hline $\begin{array}{l}\text { Housing situation } \\
\text { Solitarily Living } \\
\text { Living with others }\end{array}$ & $\begin{array}{l}9(29.0 \%) \\
22(71.0 \%) \\
54\end{array}$ & $\begin{array}{l}26(18.8 \%) \\
112(81.2 \%) \\
188\end{array}$ & $\begin{array}{l}10(19.6 \%) \\
41(80.4 \%) \\
83\end{array}$ & $\begin{array}{l}45(20.5 \%) \\
175(79.5 \%) \\
325\end{array}$ & $\begin{array}{l}\chi^{2}=1.65 \\
p<0.439\end{array}$ \\
\hline $\begin{array}{l}\text { School degree } \\
\text { None /lower than middle } \\
\text { school } \\
\text { Middle school } \\
\text { High school } \\
\text { Missing }\end{array}$ & $\begin{array}{l}25(29.8 \%) \\
30(35.7 \%) \\
1\end{array}$ & $\begin{array}{l}80(25.0 \%) \\
132(41.3 \%) \\
108(33.8 \%) \\
6\end{array}$ & $\begin{array}{l}39(30.0 \%) \\
42(32.3 \%) \\
49(37.7 \%) \\
4\end{array}$ & $\begin{array}{l}\text { I } 48(27.7 \%) \\
199(37.3 \%) \\
49(35.0 \%) \\
11\end{array}$ & $\begin{array}{l}\chi^{2}=5.52 \\
p<0.170\end{array}$ \\
\hline $\begin{array}{l}\text { Occupation } \\
\text { Working } \\
\text { Not working } \\
\text { Missing }\end{array}$ & $\begin{array}{l}17(20.0 \%) \\
68(80.0 \%) \\
0\end{array}$ & $\begin{array}{l}82(25.3 \%) \\
242(74.7 \%) \\
2\end{array}$ & $\begin{array}{l}27(20.5 \%) \\
105(79.5 \%) \\
2\end{array}$ & $\begin{array}{l}126(23.3 \%) \\
415(76.7 \%) \\
4\end{array}$ & $\begin{array}{l}\chi^{2}=1.85 \\
p<0.397\end{array}$ \\
\hline
\end{tabular}

Notes: The number of cases and in brackets the percentages are reported. To compare the cells for those variables which had more than two manifestations, Z-tests were calculated: values in the same row where the subscript is not the same, are very different at $p<0.05$ in the duplicate test for equality for column shares, corrected with Bonferroni. Significant $p$-values are presented in bold. In case of age, univariate analysis of variance was used regarding the mean score.

\section{Instruments}

Stendal Adherence to Medication Score $(\alpha=0.85) .{ }^{34}$ The SAMS assesses adherence to medication in using a 5-point, Likert-type scale ( $0=$ "never", to $4=$ "most of the time"). It comprises 18 items and 5 additional items that can be administered in inpatient settings $(0=$ "not at all", to $4=$ "very strongly"). The full SAMS and the handbook are available online (CC BY NC 3.0 licence). ${ }^{34}$ SAMS was used to investigate the non-adherence to medication in patients after renal transplantation, in patients suffering from chronic pain ${ }^{35}$ and in neurological patients (eg, Parkinson's disease). ${ }^{36}$ The SAMS has been used as it is a promising method to detect drug adherence. ${ }^{34}$ It comprehensively covers different aspects of personal reasons of nonadherence: modification of medication, missing knowledge of medication, and forgetting of medication. Using the SAMS total score (items 1-18), we can differentiate 3 levels of medication adherence:

- Complete adherence: Individuals with a sum score of 0 are defined as completely adherent.

- Non-adherent: Those $25 \%$ of participants with the highest sum scores are categorized as non-adherent. ${ }^{3}$ The cutoff differs between samples and disease groups. ${ }^{35}$ In the validation sample and the current subsample, the cutoff was a sum score of $\geq 10$. 
- Moderately adherent: Participants with scores higher than 0 and lower than the cutoff for nonadherence are categorized as moderately adherent.

Essen Coping Questionnaire $(\alpha=0.89) .{ }^{37}$ The ECQ assesses emotional, cognitive and behavioral coping in chronically ill patients, using a 5-point, Likert-type scale $(0=$ "not at all", to 4 = "extremely"). It captures distinct forms of Acting, problem-oriented coping $(\alpha=0.81)$, Distance and selfpromotion $(\alpha=0.68)$, Information seeking and exchange of experiences $(\alpha=0.82)$, Trivialisation, wishful thinking and defence $(\alpha=0.53)$, Depressive processing $(\alpha=0.72)$, Willingness to accept help $(\alpha=0.59)$, Active search for social integration $(\alpha=0.78)$, Trust in medical care $(\alpha=0.30)$, and Finding of inner stability $(\alpha=0.56)$.

\section{Analysis}

Values are given as mean and standard deviation or median and interquartile range. Categorical variables are presented as numbers or percentages. For all analyses, the significance level was set at $p<0.05$.

First, the three groups with complete, moderate, and non-adherent behaviour were determined based on the distribution form of the SAMS responses. The differences between these three groups were investigated in terms of sociodemographic and clinical variables by using Chisquared test and univariate analysis of variance. Differences regarding psychological variables were analysed using multivariate analysis of variance (Wilks Lambda) and identified variables of further interest for univariate analysis. Post-hoc comparisons used correction after Bonferroni in case of variance homogeneity or GamesHowell correction in case variance heterogeneity, determined using Levene's-test. After controlling for significant sociodemographic covariates, the remaining psychological variables were further investigated on the item-level.

\section{Results}

\section{Medication Use and Adherence Use of Medication}

The clinical data of the sample are provided in Table 2. On average, this sample consumed $5.7( \pm 3.6,1-21)$ different drugs per day, with a pill intake of $3.5( \pm 2.2,0-11)$ pills in the morning, $0.9( \pm 1.2,0-5)$ pills at noon, $2.1( \pm 1.6,0-8)$ pills in the evening. On average, they took $6.7( \pm 4.2,1-$ 19) pills per day.

\section{Medication Adherence}

The distribution of the adherence score is depicted in Figure 1. The mean sum score was $6.8( \pm 8.3,0-71)$. Onesixth of the sample $(15.6 \%)$ reported complete adherence with a sum score of 0 . A sum score between 1 and 9 was reported by $59.8 \%$ of the sample, with a mean of 4.2 ( \pm 2.3). $24.6 \%$ of the sample were classified as non-adherent with a sum score of 10 or higher, with a mean of 17.7 $( \pm 10.1)$.

\section{Adherence Groups Sociodemographics}

The three adherence groups were compared in terms of age, sex, marital status, housing situation, school degree, occupation, and whether they had a neurological disease or not. A statistically significant difference was found regarding $\operatorname{sex}\left(\mathrm{X}^{2}=6.27, p<0.043\right)$. Men were significantly less often classified as completely adherent (12.8\% vs $19.6 \%)$, but more often classified as moderately adherent $(63.7 \%$ vs $54.2 \%$ ). No sex difference was found in the nonadherent group.

\section{Use of Medication}

No differences between adherence groups were found regarding the number of medications, pills, and intake times (Table 2).

\section{Coping with Disease}

The three adherence groups differed significantly regarding coping assessed with the ECQ questionnaire $(F(18$, $1068)=1.88, p<0.014)$. Univariate comparisons regarding the subscales of the ECQ are presented in Table 3: Completely adherent participants reported significantly higher levels of Distance and self-promotion compared to non-adherent patients, $p<0.035$, higher levels of Trivialisation, wishful thinking and defence compared to moderate and non-adherent patients, $p<0.016$ and $p<0.011$, and Finding of inner stability, compared to moderate and non-adherent participants, $p<0.034$ and $p<0.025$. These subscales were further analysed with additional regard to sex, age group, school degree, and diagnosis. Besides the association of distance and selfpromotion with adherence groups, an association with age group $(p=0.014)$ and school degree $(p=0.027)$ was found. The impact of the adherence group factor lost significance $(p=0.099)$ after controlling for age ( $p=$ $0.002)$ and education $(p=0.015)$. 
Table 2 Clinical Data for Adherence Groups

\begin{tabular}{|c|c|c|c|c|c|}
\hline Variable & $\begin{array}{l}\text { Completely } \\
\text { Adherent }\end{array}$ & $\begin{array}{l}\text { Moderately } \\
\text { Adherent }\end{array}$ & $\begin{array}{l}\text { Non- } \\
\text { Adherent }\end{array}$ & $\begin{array}{l}\text { Total } \\
\text { Sample }\end{array}$ & $\begin{array}{l}\text { Group } \\
\text { Comparison }\end{array}$ \\
\hline$n$ & 85 & 326 & 134 & 545 & \\
\hline $\begin{array}{l}\text { Diagnosis } \\
\text { Neurological } \\
\text { No Neurological } \\
\text { Missing }\end{array}$ & $\begin{array}{l}49(72.1 \%) \\
19(27.9 \%) \\
17\end{array}$ & $\begin{array}{l}194(64.9 \%) \\
105(35.1 \%) \\
27\end{array}$ & $\begin{array}{l}90(73.2 \%) \\
33(76.8 \%) \\
11\end{array}$ & $\begin{array}{l}333(68.0 \%) \\
157(32.0 \%) \\
55\end{array}$ & $\begin{array}{l}\chi^{2}=3.36 \\
p<0.187\end{array}$ \\
\hline $\begin{array}{l}\text { Preparation of medication } \\
\text { by: } \\
\text { Patient } \\
\text { Family/spouse } \\
\text { Nurse/caretaker } \\
\text { Missing }\end{array}$ & $\begin{array}{l}61(83.6 \%) \\
8(11.0 \%) \\
4(5.5 \%) \\
12\end{array}$ & $\begin{array}{l}242(77.8 \%) \\
54(17.4 \%) \\
15(4.8 \%) \\
15\end{array}$ & $\begin{array}{l}98(78.4 \%) \\
24(19.2 \%) \\
3(2.4 \%) \\
9\end{array}$ & & $\begin{array}{l}\chi^{2}=3.68 \\
p<0.451\end{array}$ \\
\hline$n$ & 50 & 177 & 78 & 305 & \\
\hline Number of drugs & $5.58 \pm 3.44$ & $5.59 \pm 3.56$ & $6.06 \pm 3.65$ & $5.71 \pm 3.56$ & $\begin{array}{l}F=0.52 \\
p<0.593\end{array}$ \\
\hline$n$ & 25 & 120 & 44 & 189 & \\
\hline Pills & $7.56 \pm 3.85$ & $6.65 \pm 4.45$ & $6.23 \pm 3.72$ & $6.67 \pm 4.21$ & $\begin{array}{l}F=0.80 \\
p<0.450\end{array}$ \\
\hline Pills - morning & $3.76 \pm 1.76$ & $3.66 \pm 2.35$ & $3.09 \pm 2.17$ & $3.54 \pm 2.24$ & $\begin{array}{l}F=1.18 \\
p<0.311\end{array}$ \\
\hline Pills - noon & $1.40 \pm 1.50$ & $0.77 \pm 1.11$ & $0.86 \pm 1.25$ & $0.87 \pm 1.21$ & $\begin{array}{l}F=2.88 \\
p<0.059\end{array}$ \\
\hline Pills - evening & $2.08 \pm 1.58$ & $2.05 \pm 1.66$ & $2.11 \pm 1.40$ & $2.07 \pm 1.59$ & $\begin{array}{l}F=0.03 \\
p<0.974\end{array}$ \\
\hline Additional pills & $0.32 \pm 1.03$ & $0.18 \pm 1.04$ & $0.16 \pm 0.57$ & $0.19 \pm 0.95$ & $\begin{array}{l}F=0.27 \\
p<0.763\end{array}$ \\
\hline
\end{tabular}

Those two scales with no significant covariate were further analysed on the item level; differences between the adherence groups are presented in Table 4. Post hoc comparisons using Bonferroni correction revealed on the scale Trivialisation, wishful thinking and defence, that completely adherent participants more often agreed to item 13 "I refuse to accept my condition" compared to moderately adherent and non-adherent participants, $p<0.001$ and $p<$ 0.035 . Also, the completely adherent participants agreed more to item 23 "I keep on living as if nothing has happened" compared to non-adherent patients, $p<0.003$. Regarding the scale Finding of inner stability, completely adherent participants more often agreed to item 28 "I start to see a purpose in the disease" compared to moderately adherent and non-adherent patients, $p<0.001$ and $p<$ 0.020. Also, completely adherent participants revealed higher levels on item 42 "I regain my inner strength" compared to non-adherent participants, $p<0.030$.

\section{Discussion}

This study investigated individuals from a neurological clinic regarding medication adherence and coping with disease. The sample was derived from one validation sample of $\mathrm{SAMS}^{34}$ and comprised those 545 individuals who provided full data on their coping behaviour. The current sample was, on average, 63 years old and took 5.7 different drugs and 6.7 pills per day. For comparison: The average elderly German of $65+$ years of age with statutory health insurance consumes 3.6 doses of longterm medication. ${ }^{38}$ Polypharmacy can serve as indicator for multimorbidity. The higher number of pills per day in our cohort might therefore reflect multimorbidity. This is 


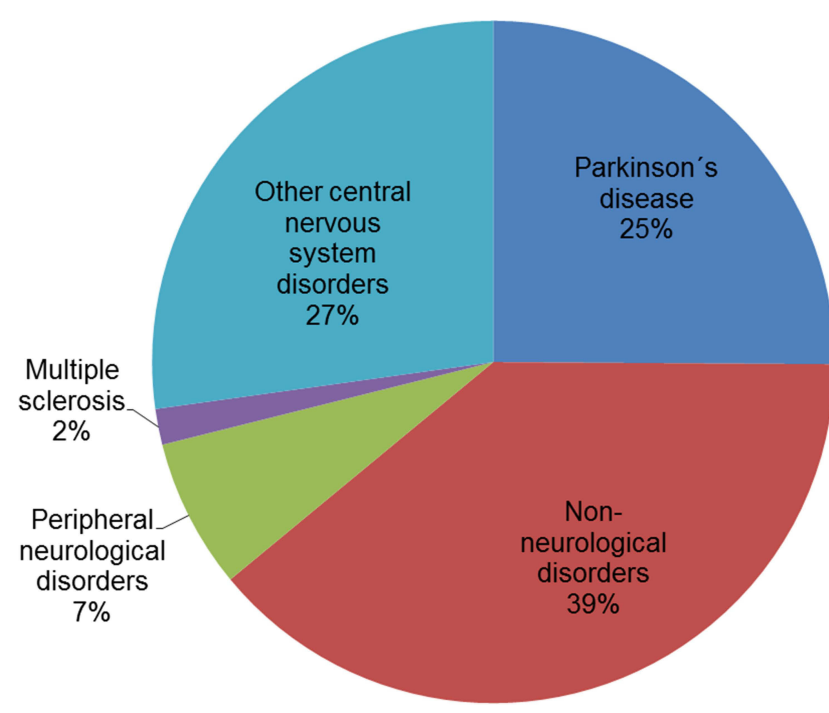

Figure I Frequencies of self-reported disorders in $n=545$ patients from a neurological clinic.

not surprising in cohort of people who are hospitalized or treated in specialized university outpatient units. ${ }^{39}$ Polypharmacy is a common phenomenon in elderly people and was found to be associated with non-adherence to medication ${ }^{40}$ However, no association was found in this sample. This can have several reasons. Overall, the medication regimen of our sample seems rather complex compared to other samples. With this number of drugs to be taken, it seems likely that possible effects and benefits of the individual drugs were not known, which might have made non-adherence more likely. Only $15.6 \%$ were classified as fully adherent, which is lower compared to other chronically ill elderly people in Germany. ${ }^{41}$ On the other hand, kidney transplant patients, for example, take about 14 drugs per day, and at the same time their drug adherence is high $(29 \%$ reported SAMS $=0) .{ }^{34,42}$ Our sample reported a rather high rate of insufficient adherence with a mean SAMS score of $6.8( \pm 8.3)$, which is higher than in kidney transplant patients $\left(2.9 \pm 3.3^{34}, t=9.07, p<0.001\right)$, but lower than in chronic pain patients $\left(8.8 \pm 7.7^{34}, t=\right.$ $3.27, p<0.01)$. Thus, the frequently discussed differences in medication adherence between different patient groups ${ }^{3}$ are also confirmed by the results of this study. Moreover, one has to keep in mind that we assessed self-report adherence. This might also explain the lacking association between polypharmacy and non-adherence which was found in studies using objective methods (eg, electronic pill counting) to assess adherence.

Regarding sociodemographics and clinical data, only gender was confirmed as a differentiating variable. Men were less often classified as completely adherent and more often classified as moderately adherent, which contradicts previous findings of women being less adherent than men in the $\mathrm{US}^{43}$ and specifically in patients with dementia. ${ }^{44}$

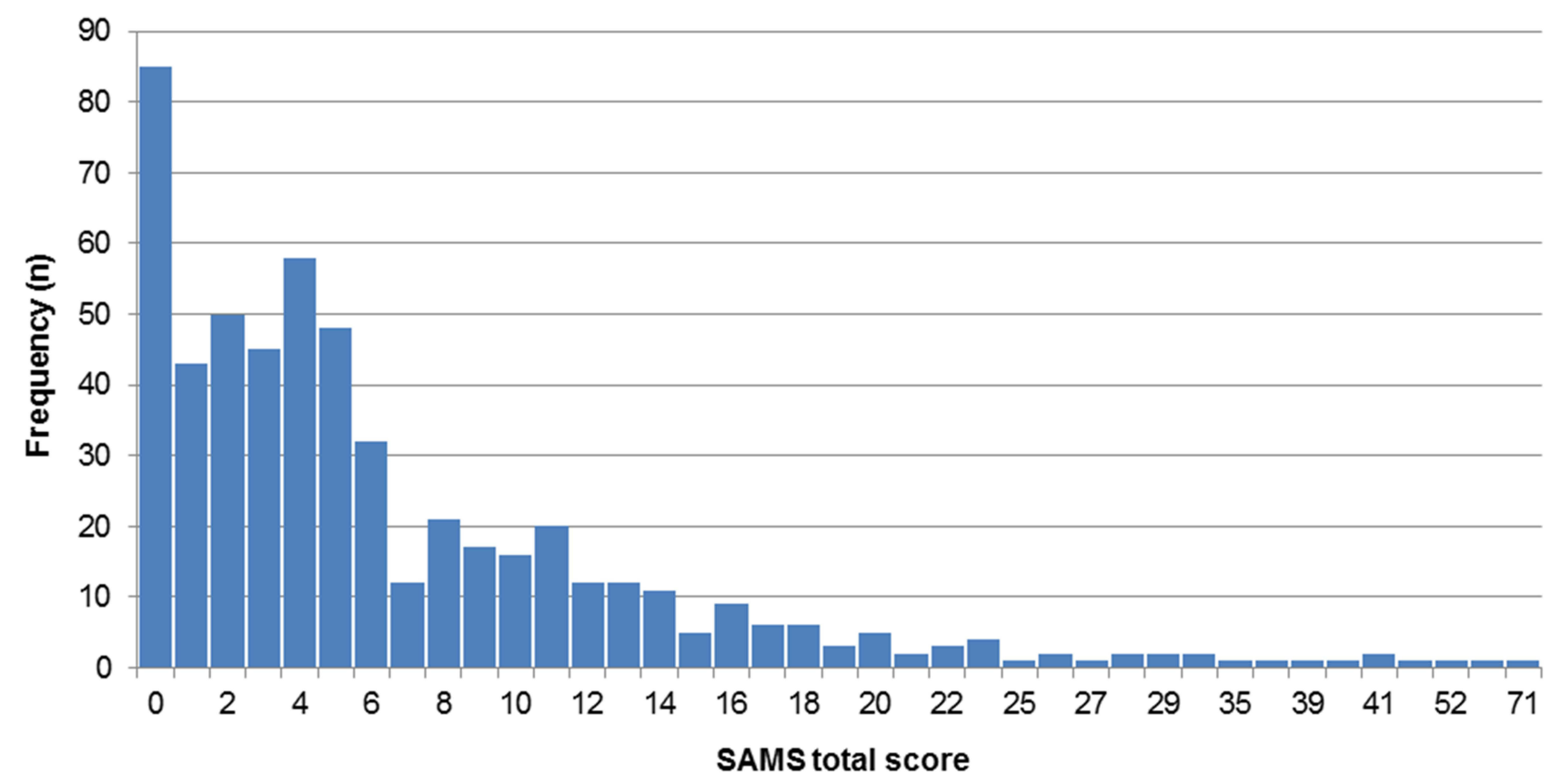

Figure 2 Distribution of Stendal Adherence to Medication Score (SAMS) total score. 
Table 3 Differences Between Adherence Groups on Coping with Disease

\begin{tabular}{|c|c|c|c|c|c|}
\hline Variable & $\begin{array}{l}\text { Completely } \\
\text { Adherent }\end{array}$ & $\begin{array}{l}\text { Moderately } \\
\text { Adherent }\end{array}$ & $\begin{array}{l}\text { Non- } \\
\text { Adherent }\end{array}$ & $\begin{array}{l}\text { Total } \\
\text { Sample }\end{array}$ & $\begin{array}{l}\text { Group } \\
\text { Comparison }\end{array}$ \\
\hline $\mathbf{N}$ & 85 & 326 & 134 & 545 & \\
\hline ECQ-I Stanine Acting, problem-oriented coping & $5.21 \pm 2.08$ & $5.23 \pm 2.03$ & $4.90 \pm 1.84$ & $5.15 \pm 1.99$ & $\begin{array}{l}F=1.40 \\
p<0.248\end{array}$ \\
\hline ECQ-2 Stanine Distance and self-promotion & $5.66 \pm 1.95$ & $5.21 \pm 2.02_{1,2}$ & $4.98 \pm 1.75_{2}$ & $5.22 \pm 1.95$ & $\begin{array}{l}F=3.22 \\
p<0.04 I^{\dagger}\end{array}$ \\
\hline $\begin{array}{l}\text { ECQ-3 Stanine Information seeking and exchange } \\
\text { of experiences }\end{array}$ & $5.35 \pm 2.30$ & $5.06 \pm 2.13$ & $5.41 \pm 1.94$ & $5.19 \pm 2.12$ & $\begin{array}{l}F=1.65 \\
p<0.194\end{array}$ \\
\hline $\begin{array}{l}\text { ECQ-4 Stanine Trivialisation, wishful thinking and } \\
\text { defence }\end{array}$ & $5.79 \pm 1.83$ & $5.16 \pm 1.87_{2,3}$ & $5.04 \pm 1.78_{3}$ & $5.23 \pm 1.85$ & $\begin{array}{l}F=4.82 \\
p<0.008\end{array}$ \\
\hline ECQ-5 Stanine Depressive processing & $5.71 \pm 1.94$ & $5.62 \pm 1.80$ & $5.97 \pm 1.64$ & $5.72 \pm 1.79$ & $\begin{array}{l}F=1.87 \\
p<0.156\end{array}$ \\
\hline ECQ-6 Stanine Willingness to accept help & $5.61 \pm 1.83$ & $5.17 \pm 1.68$ & $5.23 \pm 1.88$ & $5.26 \pm 1.76$ & $\begin{array}{l}F=2.11 \\
P<0.122\end{array}$ \\
\hline ECQ-7 Stanine Active search for social integration & $5.13 \pm 1.76$ & $4.68 \pm 2.02$ & $4.54 \pm 2.03$ & $4.71 \pm 1.99$ & $\begin{array}{l}F=2.45 \\
p<0.087\end{array}$ \\
\hline ECQ-8 Stanine Trust in medical care & $6.49 \pm 1.55$ & $6.7 I \pm 1.68$ & $6.34 \pm 1.59$ & $6.59 \pm 1.64$ & $\begin{array}{l}F=2.56 \\
p<0.078\end{array}$ \\
\hline ECQ-9 Stanine Finding of inner stability & $4.98 \pm 1.67$ & $4.46 \pm 1.65_{2}$ & $\begin{array}{l}4.37 \pm \\
1.68_{2,3}\end{array}$ & $4.52 \pm 1.67$ & $\begin{array}{l}F=3.99 \\
p<0.019\end{array}$ \\
\hline
\end{tabular}

Notes: For significant analyses of variance, post-hoc-tests were calculated: values in the same row where the subscript is not the same are significantly different at $p<0.05$, corrected with Bonferroni. Significant $p$-values are presented in bold. ${ }^{\dagger}$ After controlling for age and school degree, this association was not statistically significant.

Contradicting previous studies in neurological patients, ${ }^{6,7,14,17,44}$ age, education, employment, and medication regimen were not associated with adherence. Additionally, no differences were found comparing patients with diseases of the nervous systems with other disease groups. However, it is important to note that the classification by disease was based on what the patients themselves stated in the questionnaire. This does not necessarily correspond to the main and secondary diagnoses recorded by the doctor. A review of the diagnoses and a possibly more correct classification according to the medical record were not carried out in this study.

Regarding coping, adherence was associated with higher levels of Finding of inner stability, as well as Trivialisation and wishful thinking. This is in line with a previous finding linking adherence to higher levels of self-efficacy in patients with epilepsy ${ }^{45}$ or multiple sclerosis ${ }^{46}$ as well as findings of higher levels of motivation, willpower and positive attitudes towards disease and treatment in epileptic youth. ${ }^{47}$ Specifically, completely adherent patients were more likely to report not accepting their condition and to keep on living as nothing has happened, which might be indicative of their perceived self-efficacy. Adherence was also associated with seeing a purpose in the disease - which could be an indicator of inner peace - as well as regaining inner strength. Both are associated with mindfulness. ${ }^{48,49}$ Mindfulness is positively associated with medication adherence in Alzheimer patients $^{50}$ and a recent review considered mindfulness training a promising intervention to increase medication adherence. ${ }^{51}$ No differences were found regarding the scales focusing on active coping strategies. Overall, it seems that fully adherent patients focus more on distraction and indulgence rather than on their illness and improving their whole lifestyle. This is in line with previous research showing that patients with epilepsy may be adherent with medication, but not with healthful lifestyle behaviours. ${ }^{45,52}$

According to the WHO, interventions to ensure and increase adherence must be individually tailored to the specific disease-related needs of the patient. ${ }^{24}$ Common interventions such as psychoeducation and counselling might be of help to 
Table 4 Differences Between Adherence Groups on Coping with Disease Items

\begin{tabular}{|c|c|c|c|c|c|}
\hline Variable & $\begin{array}{l}\text { Completely } \\
\text { Adherent }\end{array}$ & $\begin{array}{l}\text { Moderately } \\
\text { Adherent }\end{array}$ & $\begin{array}{l}\text { Non- } \\
\text { Adherent }\end{array}$ & $\begin{array}{l}\text { Total } \\
\text { Sample }\end{array}$ & $\begin{array}{l}\text { Group } \\
\text { Comparison }\end{array}$ \\
\hline $\mathbf{N}$ & 85 & 326 & 134 & 545 & \\
\hline \multicolumn{6}{|l|}{ ECQ-4 Trivialisation, wishful thinking and defence } \\
\hline 5. I lose myself in daydreams & $1.26 \pm 1.21$ & $1.07 \pm 1.23$ & $1.16 \pm 1.21$ & $\begin{array}{l}1.12 \pm \\
1.22\end{array}$ & $\begin{array}{l}F=0.91 \\
p<0.403\end{array}$ \\
\hline 13. I refuse to accept my condition & $1.48 \pm 1.27$ & $0.98 \pm 1.15_{2}$ & $\begin{array}{l}1.07 \pm \\
1.12_{2}\end{array}$ & $\begin{array}{l}1.08 \pm \\
1.17\end{array}$ & $\begin{array}{l}F=6.34 \\
P<\mathbf{0 . 0 0 2}\end{array}$ \\
\hline 23. I keep on living as if nothing has happened & $1.94 \pm 1.31$ & $1.69 \pm 1.28_{1}$ & $\begin{array}{l}1.36 \pm \\
1.14_{2}\end{array}$ & $\begin{array}{l}1.65 \pm \\
1.27\end{array}$ & $\begin{array}{l}F=6.09 \\
p<0.002\end{array}$ \\
\hline 39. I downplay the significance and importance & $1.13 \pm 1.14$ & $1.01 \pm 1.06$ & $0.93 \pm 0.93$ & $\begin{array}{l}1.01 \pm \\
1.04\end{array}$ & $\begin{array}{l}F=1.00 \\
p<0.370\end{array}$ \\
\hline 43. I do not think about my illness anymore & $1.64 \pm 1.21$ & $1.52 \pm 1.15$ & $1.40 \pm 1.18$ & $\begin{array}{l}1.51 \pm \\
1.17\end{array}$ & $\begin{array}{l}F=1.16 \\
p<0.316\end{array}$ \\
\hline \multicolumn{6}{|l|}{ ECQ-9 Finding of inner stability } \\
\hline $\begin{array}{l}\text { II. I pick myself up through prayer, meditation or intense } \\
\text { contact with nature }\end{array}$ & $1.04 \pm 1.20$ & $0.90 \pm 1.25$ & $0.91 \pm 1.26$ & $\begin{array}{l}0.92 \pm \\
1.25\end{array}$ & $\begin{array}{l}F=0.40 \\
P<0.672\end{array}$ \\
\hline 28. I start to see a purpose in the disease & $1.06 \pm 1.21_{1}$ & $0.63 \pm 0.94_{2}$ & $\begin{array}{l}0.68 \pm \\
1.02_{2}\end{array}$ & $\begin{array}{l}0.71 \pm \\
1.01\end{array}$ & $\begin{array}{l}F=6.26 \\
p<0.002\end{array}$ \\
\hline 3I. I pray and seek solace in faith & $0.49 \pm 0.83$ & $0.53 \pm 1.14$ & $0.43 \pm 0.79$ & $\begin{array}{l}0.50 \pm \\
1.02\end{array}$ & $\begin{array}{l}F=0.5 I \\
p<0.60 I\end{array}$ \\
\hline 37. I start to accept the disease as my fate & $1.78 \pm 1.32$ & $1.49 \pm 1.22$ & $1.43 \pm 1.18$ & $\begin{array}{l}1.52 \pm \\
1.23\end{array}$ & $\begin{array}{l}F=2.26 \\
p<0.105\end{array}$ \\
\hline 42. I regain my inner strength & $2.11 \pm 1.02_{1}$ & $\mathrm{I} .82 \pm \mathrm{I} . \mathrm{II}_{\mathrm{I}, 2}$ & $\begin{array}{l}1.72 \pm \\
1.07_{2}\end{array}$ & $\begin{array}{l}1.84 \pm \\
1.09\end{array}$ & $\begin{array}{l}F=3.47 \\
p<\mathbf{0 . 0 3 2}\end{array}$ \\
\hline
\end{tabular}

Notes: For significant analyses of variance, post-hoc-tests were calculated: values in the same row where the subscript is not the same are significantly different at $p<0.05$, corrected with Bonferroni. Significant $p$-values are presented in bold.

improve coping. ${ }^{53}$ Because self-efficacy is a strong predictor of medication adherence, ${ }^{54,55}$ empowering patients to effectively cooperate with their physician might additionally increase adherence, ${ }^{56}$ improving the therapeutic alliance may be one way to empower them ${ }^{57}$ and to increase adherence. ${ }^{6,58}$ Patients could also benefit from mindfulness training.

Adherence is a dynamic process that must be followed and reviewed. The extent to which the SAMS can be used for repeat measurements, eg, after interventions to improve adherence, needs to be investigated in future studies.

This study is not free of limitations. Its monocentric design and focus on patients from a university hospital limits the generalizability of the results. Although the sample size is comparable to other studies in people with neurological disorders, results should only be generalized with caution. Multicentre studies with larger sample sizes are necessary to make confirmatory statements about the association between adherence and coping styles in different populations and cohorts. Of the initial sample, only two-thirds provided full questionnaire data, the other third had to be excluded. Analysis showed no non-response bias regarding the level of medication adherence. Nevertheless, those excluded were significantly older, which is in line with previous research identifying old age as a strong determinant of partial nonresponse. ${ }^{59,60}$ In addition, only self-reported questionnaires were used for analyses. No additional assessments (eg, rating scales for depression or cognition) or data from medical records were collected for this exploratory study. Therefore, cognitive impairment cannot be ruled out as limitation. However, less than 
$0.6 \%$ reported dementia as diagnosis and previous research showed that patients with mild to moderate dementia can provide reliable answers, nonetheless. ${ }^{61}$ Future studies should confirm the association between different coping styles and adherence by incorporating relevant cofactors such as depression, multimorbidity and cognitive function.

\section{Conclusion}

Overall, self-reported medication adherence in this group of patients from a neurological hospital was low compared to other patient groups. The approach of classifying the patients with no adherence problems as fully adherent and the $25 \%$ of patients with the highest non-adherence values as non-adherent has proven to be useful. Some group differences were found, mainly regarding different facets of coping. This has several implications for clinical practice and research. Beside common predictors of nonadherence, coping with disease is a promising target for interventions to improve adherence. Following the results of this study, interventions to improve medication adherence in patients with neurological disorders should aim to improve the patients coping strategies in terms of accepting the chronic condition of the disease, strengthening willpower and self-efficacy, and enhancing a positive attitude towards the treatment. Therefore, a well-coordinated overall treatment plan and managed communication between treatment providers is essential.

\section{Disclosure}

Dr Tino Prell reports grants from Bundesministerium für Bildung und Forschung (BMBF), during the conduct of the study (01GY1804). The authors report no conflicts of interest in this work.

\section{References}

1. Osterberg L, Blaschke T. Adherence to medication. $N$ Eng $J$ Med. 2005;353:487-497. doi:10.1056/NEJMra050100

2. Simpson SH, Eurich DT, Majumdar SR, et al. A meta-analysis of the association between adherence to drug therapy and mortality. BMJ. 2006;333(7557):15. doi:10.1136/bmj.38875.675486.55

3. DiMatteo MR. Variations in patients' adherence to medical recommendations: a quantitative review of 50 years of research. Med Care. 2004;42(3):200-209. doi:10.1097/01.mlr.0000114908.90348.f9

4. Vermeire E, Hearnshaw H, van Royen P, Denekens J. Patient adherence to treatment: three decades of research. A comprehensive review. $J$ Clin Pharm Ther. 2001;26(5):331-342. doi:10.1046/j.13652710.2001.00363.x

5. Roter DL, Hall JA, Merisca R, Nordstrom B, Cretin D, Svarstad B. Effectiveness of interventions to improve patient compliance: a meta-analysis. Med Care. 1998;36(8):1138-1161. doi:10.1097/ 00005650-199808000-00004
6. Malek N, Heath CA, Greene J. A review of medication adherence in people with epilepsy. Acta Neurol Scand. 2017;135(5):507-515. doi:10.1111/ane. 12703

7. Specht U. Medikamenten-Compliance bei Epilepsie [Compliance with antiepileptic drugs]. Nervenarzt. 2008;79(6):662-668. doi:10.1007/s00115-008-2408-3

8. Petermann F, Tampe T. Compliance bei chronisch kranken Kindern und Jugendlichen [Compliance in children and adolescents with chronic illness]. Kindheit und Entwicklung. 2002;11(1):3-13. doi:10.1026//0942-5403.11.1.3

9. Jarvie S. Epilepsy knowledge, beliefs and education. In: Pfäfflin M, Fraser RT, Thorbecke R, Specht U, Wolf P, editors. Comprehensive Care for People with Epilepsy. Eastleigh: John Libbey \& Company Ltd; 2001:23-34.

10. Long L, Reeves AL, Moore JL, Roach J, Pickering CT. An assessment of epilepsy patients' knowledge of their disorder. Epilepsia. 2000;41(6):727-731. doi:10.1111/j.1528-1157.2000.tb00235.x

11. Nerius M, Ziegler U, Doblhammer G, Fink A. Trends in der Prävalenz von Demenz und Parkinson - eine Analyse auf Basis aller gesetzlich versicherten Personen im Alter 65+ in Deutschland zwischen 2009 und 2012 [Trends in the Prevalence of Dementia and Parkinson's Disease: an Analysis Based on Health Claims Data from all German Statutory Health Insurance Funds for Persons aged 65+ in Germany 2009-2012]. Gesundheitswesen. 2020;82(10):761-769. doi:10.1055/a-0829-6494

12. Davis KL, Edin HM, Allen JK. Prevalence and cost of medication nonadherence in Parkinson's disease: evidence from administrative claims data. Mov Disord. 2010;25(4):474-480. doi:10.1002/mds.22999

13. Leoni O, Martignoni E, Cosentino M, et al. Drug prescribing patterns in Parkinson's disease: a pharmacoepidemiological survey in a cohort of ambulatory patients. Pharmacoepidemiol Drug Saf. 2002;11 (2):149-157. doi:10.1002/pds.682

14. Grosset KA, Bone I, Grosset DG. Suboptimal medication adherence in Parkinson's disease. Mov Disord. 2005;20(11):1502-1507. doi: $10.1002 / \mathrm{mds} .20602$

15. Á S, Arbelo JM, Del Val JL. Treatment of Parkinson disease, time and dosage: "does simple dosage facilitate compliance and therapeutic goals?". Neurologist. 2011;17:S43-46. doi:10.1097/ NRL.0b013e31823968d3

16. Wei Y-J, Palumbo FB, Simoni-Wastila L, et al. Antiparkinson drug use and adherence in medicare part $\mathrm{d}$ beneficiaries with Parkinson's disease. Clin Ther. 2013;35(10):1513-1525. doi:10.1016/j. clinthera.2013.09.001

17. Malek N, Grosset DG. Medication adherence in patients with Parkinson's disease. CNS Drugs. 2015;29(1):47-53. doi:10.1007/ s40263-014-0220-0

18. Daley DJ, Myint PK, Gray RJ, Deane KHO. Systematic review on factors associated with medication non-adherence in Parkinson's disease. Parkinsonism Relat Disord. 2012;18(10):1053-1061. doi:10.1016/j.parkreldis.2012.09.004

19. Nguyen T-M-U, La Caze A, Cottrell N. What are validated self-report adherence scales really measuring?: a systematic review. Br J Clin Pharmacol. 2014;77(3):427-445. doi:10.1111/bcp.12194

20. Morisky DE, Green LW, Levine DM. Concurrent and predictive validity of a self-reported measure of medication adherence. Med Care. 1986;24(1):67-74. doi:10.1097/00005650-198601000-00007

21. Morisky DE, Ang A, Krousel-Wood M, Ward HJ. Predictive validity of a medication adherence measure in an outpatient setting. $J$ Clin Hypertens. 2008;10(5):348-354. doi:10.1111/j.1751-7176.2008.07572.x

22. Culig J, From LM. Morisky to Hill-bone; self-reports scales for measuring adherence to medication. Coll Antropol. 2014;38 (1):55-62.

23. Vrijens B, De Geest S, Hughes DA. Geest S de, Hughes DA, et al. A new taxonomy for describing and defining adherence to medications. $\mathrm{Br} \quad J$ Clinl Pharmacol. 2012;73(5):691-705. doi:10.1111/j.1365-2125.2012.04167.x 
24. Sabaté E. Adherence to long-Term Therapies: Evidence for Action. Geneva: World Health Organization; 2003.

25. Tosin MHS, Stebbins GT, Goetz CG, Santana RF, Leite MAA, Oliveira BGR. Measuring medication adherence in Parkinson's disease: a systematic review of contributing components in rating scales. Mov Disord Clin Pract. 2020;7(6):607-615. doi:10.1002/mdc3.13006

26. Kristofferzon M-L, Engström M, Nilsson A. Coping mediates the relationship between sense of coherence and mental quality of life in patients with chronic illness: a cross-sectional study. Qual Life Res. 2018;27(7):1855-1863. doi:10.1007/s11136-018-1845-0

27. Martz E, Livneh H, eds. Coping with Chronic Illness and Disability. New York: Springer; 2007.

28. Mikula P, Nagyova I, Krokavcova M, et al. Coping and its importance for quality of life in patients with multiple sclerosis. Disabil Rehabil. 2014;36(9):732-736. doi:10.3109/09638288.2013.808274

29. Backer JH. Stressors, social support, coping, and health dysfunction in individuals with Parkinson's disease. J Gerontol Nurs. 2000;26 (11):6-9. doi:10.3928/0098-9134-20001101-05

30. Frazier LD. Coping with disease-related stressors in Parkinson's disease. Gerontologist. 2000;40(1):53-63.

31. Schreurs KMG, De Ridder DTD, Bensing JM. A one year study of coping, social support and quality of life in Parkinson's disease. Psychol Health. 2000;15(1):109-121. doi:10.1080/08870440008400292

32. Montel S, Bonnet A-M BC. Quality of life in relation to mood, coping strategies, and dyskinesia in Parkinson's disease. J Geriatr Psychiatry Neurol. 2009;22(2):95-102. doi:10.1177/ 0891988708328219

33. Bucks RS, Cruise KE, Skinner TC, Loftus AM, Barker RA, Thomas MG. Coping processes and health-related quality of life in Parkinson's disease. Int J Geriatr Psychiatry. 2011;26(3):247-255. doi:10.1002/gps.2520

34. Franke GH, Nentzl J, Jagla-Franke M. SAMS - Stendal Adherence with Medication Score.: deutsches Manual. Psychometrikon. 2020. Available from: https://www.psychometrikon.de/inhalt/suchen/test. php?id=ff32ee9ea015021c3fb047e505e2bc45. Accessed April 17, 2021.

35. Franke GH, Nentzl J, Küch D, Die J-FM. Erfassung der MedikamentenAdhärenz bei Schmerzpatientinnen und -patienten [Assessment of adherence to medication in pain patients]. Klinische Verhaltensmedizin und Rehabilitation. 2020;33(2):27-39.

36. Prell T, Grosskreutz J, Mendorf S, Franke GH, Witte OW, Kunze A. Clusters of non-adherence to medication in neurological patients. Res Social Adm Pharm. 2019;15(12):1419-1424. doi:10.1016/j. sapharm.2019.01.001

37. Franke GH, Jagla M ECQ - essen Coping Questionnaire Test Manual - English version. Psychometrikon. Available from: http:// psychometrikon.de/inhalt/suchen/test.php? id= b2c6285c00324df0956e23257eb0e176. Accessed April 17, 2021.

38. Coca V, Nink K, Schröder H. Arzneimittelverordnungen nach Alter und Geschlecht. In: Schwabe U, Paffrath D, editors. Arzneiverordnungs-Report 2007. Berlin: Springer; 2008:919-932.

39. Kruse A, Gaber E, Heuft G, Oster P, Re S, Schulz-Nieswandt F. Themenheft 10" Gesundheit im Alter". Berlin: RKI; 2002.

40. Marcum ZA, Gellad WF. Medication adherence to multidrug regimens. Clin Geriatr Med. 2012;28(2):287-300. doi:10.1016/j. cger.2012.01.008

41. Jüngst $C$, Gräber $S$, Simons $S$, Wedemeyer $H$, Lammert $F$. Medication adherence among patients with chronic diseases: a survey-based study in pharmacies. QJM. 2019;112(7):505-512. doi:10.1093/qjmed/hcz058

42. Jäger S, Franke GH, Reimer J, et al. Der Zusammenhang zwischen Medikamenten-Compliance und gesundheitsbezogener Lebensqualität bei Nierentransplantierten [Relationship between adherence to medication and health related quality of life in kidney transplanted patients]. In: Klinische Psychologie AK, im BDP, editor. Psychische Störungen in der somatischen Rehabilitation. Berlin: dpv;2009:79-93.
43. Manteuffel M, Williams S, Chen W, Verbrugge RR, Pittman DG, Steinkellner A. Influence of patient sex and gender on medication use, adherence, and prescribing alignment with guidelines. $J$ Womens Health (Larchmt). 2014;23(2):112-119. doi:10.1089/jwh.2012.3972

44. El-Saifi N, Moyle W, Jones C, Tuffaha H. Medication adherence in older patients with dementia: a systematic literature review. $J$ Pharm Pract. 2018;31(3):322-334. doi:10.1177/0897190017710524

45. Kobau R, Dilorio C. Epilepsy self-management: a comparison of self-efficacy and outcome expectancy for medication adherence and lifestyle behaviors among people with epilepsy. Epilepsy Behav. 2003;4(3):217-225. doi:10.1016/S1525-5050(03)00057-X

46. Fraser C, Morgante L, Hadjimichael O, Vollmer T. A prospective study of adherence to glatiramer acetate in individuals with multiple sclerosis. J Neurosci Nurs. 2004;36(3):120-130. doi:10.1097/ 01376517-200406000-00002

47. Kyngäs H. Compliance with health regimens of adolescents with epilepsy. Seizure. 2000;9(8):598-604. doi:10.1053/seiz.2000.0470

48. Bajaj B, Pande N. Mediating role of resilience in the impact of mindfulness on life satisfaction and affect as indices of subjective well-being. Pers Individ Dif. 2016;93:63-67. doi:10.1016/j.paid.2015.09.005

49. Liu X, Xu W, Wang Y, et al. Can inner peace be improved by mindfulness training: a randomized controlled trial. Stress Health. 2015;31(3):245-254. doi:10.1002/smi.2551

50. Lima S, Gago M, Garrett C, Pereira MG. Medication adherence in Alzheimer's disease: the mediator role of mindfulness. Arch Gerontol Geriatr. 2016;67:92-97. doi:10.1016/j.archger.2016.06.021

51. Salmoirago-Blotcher E, Carey MP. Can mindfulness training improve medication adherence? Integrative review of the current evidence and proposed conceptual model. Explore (NY). 2018;14(1):59-65. doi:10.1016/j.explore.2017.09.010

52. Dilorio C, Henry M. Self-management in persons with epilepsy. $J$ Neurosci Nurs. 1995;27(6):338-343. doi:10.1097/01376517199512000-00004

53. Nieuwlaat R, Wilczynski $\mathrm{N}$, Navarro $\mathrm{T}$. et al. Interventions for enhancing medication adherence. Cochrane Database Syst Rev;2014. 11. doi:10.1002/14651858.CD000011.pub4

54. Dunbar J. Predictors of patient adherence: patient characteristics. In: Shumaker SA, Schron EB, Ockene JK, Parker CT, Probstfield JL, Wolle JM, editors. The Handbook of Health Behavior Change. New York: Springer; 1990:348-360.

55. Lamarche L, Tejpal A, Mangin D. Self-efficacy for medication management: a systematic review of instruments. Patient Prefer Adherence. 2018;12:1279-1287. doi:10.2147/PPA.S165749

56. Náfrádi L, Nakamoto K, Schulz PJ. Is patient empowerment the key to promote adherence? A systematic review of the relationship between self-efficacy, health locus of control and medication adherence. PLoS One. 2017;12(10):e0186458. doi:10.1371/journal. pone. 0186458

57. Pagès-Puigdemont N, Mangues MA, Masip M, et al. Patients' perspective of medication adherence in chronic conditions: a qualitative study. Adv Ther. 2016;33(10):1740-1754. doi:10.1007/s12325-016-0394-6

58. Conn VS, Ruppar TM. Medication adherence outcomes of 771 intervention trials: systematic review and meta-analysis. Prev Med. 2017;99:269-276. doi:10.1016/j.ypmed.2017.03.008

59. Eaker S, Bergström R, Bergström A, Adami HO, Nyren O. Response rate to mailed epidemiologic questionnaires: a population-based randomized trial of variations in design and mailing routines. Am J Epidemiol. 1998;147(1):74-82. doi:10.1093/oxfordjournals.aje.a009370

60. Hardie JA, Bakke PS, Mørkve O. Non-response bias in a postal questionnaire survey on respiratory health in the old and very old. Scand J Public Health. 2003;31(6):411-417. doi:10.1177/ 140349480303100603

61. Trigg R, Jones RW, Skevington SM. Can people with mild to moderate dementia provide reliable answers about their quality of life? Age Ageing. 2007;36(6):663-669. doi:10.1093/ageing/afm077 


\section{Publish your work in this journal}

Patient Preference and Adherence is an international, peer-reviewed, open access journal that focusing on the growing importance of patient preference and adherence throughout the therapeutic continuum. Patient satisfaction, acceptability, quality of life, compliance, persistence and their role in developing new therapeutic modalities and compounds to optimize clinical outcomes for existing disease

states are major areas of interest for the journal. This journal has been accepted for indexing on PubMed Central. The manuscript management system is completely online and includes a very quick and fair peer-review system, which is all easy to use. Visit http:// www.dovepress.com/testimonials.php to read real quotes from published authors.

Submit your manuscript here: https://www.dovepress.com/patient-preference-and-adherence-journal 